Journal of Bangladesh Academy of Sciences, Vol. 35, No. 2, 171-178, 2011

\title{
CHARACTERIZATION AND CURIE TEMPERATURE OF CO DOPED Ni-Zn PERMINVAR FERRITE
}

\author{
MD. SOHAL RANA, RABINDRA CHANDRA SINHA* AND D.K. SAHA ${ }^{1}$
}

IUBAT-International University of Business, Agriculture and Technology, Uttara, Dhaka, Bangladesh

\begin{abstract}
$\mathrm{Ni}-\mathrm{Zn}$ perminvar ferrites having the compositions $\mathrm{Co}_{0.02} \mathrm{Zn}_{0.20} \mathrm{Ni}_{0.58} \mathrm{Fe}_{2.2} \mathrm{O}_{4}$ and $\mathrm{Co}_{0.02} \mathrm{Zn}_{0.28}$ $\mathrm{Ni}_{0.50} \mathrm{Fe}_{2.2} \mathrm{O}_{4}$ were prepared through the solid state reaction using conventional ceramic method. The homogeneous phase of perminvar ferrites has been observed from the study of $\mathrm{X}$-ray diffraction. Lattice parameter of the samples was found to be $8.369,8.372$ and $8.375 \AA$ for the sample $\mathrm{Co}_{0.02} \mathrm{Zn}_{0.20} \mathrm{Ni}_{0.58} \mathrm{Fe}_{2.2} \mathrm{O}_{4}$ and $8.382,8.383$ and $8.384 \AA$ for the sample $\mathrm{Co}_{0.02} \mathrm{Zn}_{0.28}$ $\mathrm{Ni}_{0.50} \mathrm{Fe}_{2} .2 \mathrm{O} 4$ sintered at 1200,1300 and $1350^{\circ} \mathrm{C}$ respectively. Both the bulk density and porosity decreases with $\mathrm{Zn}$ content and sintering temperatures. The values of Curie temperature of the two compositions were found to be 511,508 and $508^{\circ} \mathrm{C}$ (for $\mathrm{T}_{\mathrm{S}}=1200,1300$ and $1350^{\circ} \mathrm{C}$ ) for the sample of $\mathrm{Co}_{0.02} \mathrm{Zn}_{0.20} \mathrm{Ni}_{0.58} \mathrm{Fe}_{2.2} \mathrm{O}_{4}$ and 460 and $455^{\circ} \mathrm{C}$ (for $\mathrm{T}_{\mathrm{s}}=1300$ and $1350^{\circ} \mathrm{C}$ ) for the sample of $\mathrm{Co}_{0.02} \mathrm{Zn}_{0.28} \mathrm{Ni}_{0.50} \mathrm{Fe}_{2.2} \mathrm{O}_{4}$, respectively. Frequency dependence permeability spectra, revealed that permeability of all the samples is almost independent of frequency up to $1 \mathrm{MHz}$. It is observed that permeability increases with $\mathrm{Zn}$ content and hence the relative quality factor decreases with increasing $\mathrm{Zn}$ content.
\end{abstract}

Key words: Perminvar ferrite, Curie temperature, Initial permeability, Quality factor

\section{INTRODUCTION}

$\mathrm{Ni}-\mathrm{Zn}$ ferrite with $\mathrm{Co}, \mathrm{Cu}, \mathrm{Cd}, \mathrm{Cr}$ or $\mathrm{Mn}$ doping are known as perminvar ferrite. Ferrites are manufactured by the usual technique of ceramics. Normally the permeability of perminvar ferrite is constant in a wide range of frequency (Chikazumi 1966). The hysteresis loop is linear in shape at low amplitude of the applied magnetic field and becomes open with increasing the applied magnetic field. At high value of applied magnetic field, the hysteresis loop is similar with those of the usual Ni-Zn ferrite. At low magnetic field, Ni-Co perminvar ferrite shows wasp-waisted hysteresis loop when they are cooled in the absence of magnetic field (Chikazumi 1966). Taniguchi (1956) explained this phenomenon in terms of the fixing of domain walls by local directional order.

It is considered that if a domain wall exists during the process of cooling, two or more sorts of constituent elements of the ferrite will form a directional order, so as to

\footnotetext{
*Address for correspondence: Department of Physics, Jahangirnagar University, Savar, Dhaka, Bangladesh.

${ }^{1}$ Material Science Division, Atomic Energy Centre, Dhaka, Bangladesh.
} 
stabilize the direction of spins in the domain wall. After cooling, the wall is stabilized at its original position, so the magnetization curve starts with low permeability and then jumps to saturation magnetization as soon as the wall gets out of the stabilized position. Curie temperature of perminvar ferrite is normally $>350^{\circ} \mathrm{C}$.

$\mathrm{Ni}-\mathrm{Zn}$ perminvar ferrites with their ease of preparation and versatility for use in wide ranging applications are very attractive materials from the commercial point of view. Microstructure and magnetic properties of these ferrites are highly sensitive to preparation method, sintering conditions and amount of constituent metal oxides including impurities or dopants. Many efforts were focused in obtaining low-power loss material operating in the $\mathrm{MHz}$ region in accordance with the miniaturization of cores (Smart 1955).

The surface-mounting devices have been rapidly developed for electronic applications, such as multilayer chip beads or inductors. They are important component of latest products, such as cellular phones, video cameras, and notebook computers, hard and floppy drives. Among available materials, polycrystalline ferrites have been used widely because of their high permeability in the RF region, high electrical resistivity and environmental stability. There has been a growing interest in CoZnNi ferrites for the application in producing multilayer-type chips mainly, because these oxides can be sintered at relatively low temperatures with a wide range of compositions. In particular, the addition of $\mathrm{Co}$ in the ferrite composition has been known to play a crucial role in dropping the firing temperature. In addition, CoZnNi ferrite has better properties at high frequencies than $\mathrm{Mn}-\mathrm{Zn}$ ferrites and the lower densification temperatures than $\mathrm{Ni}-\mathrm{Zn}$ ferrites (Olofa 1994).

The present work focuses on the X-ray diffraction, density, porosity, Curie temperature, frequency dependent permeability, loss factor, quality factor etc. of Co doped Ni-Zn perminvar ferrites sintered at different temperatures.

\section{MATERIALS AND METHODS}

Ni-Zn ferrites with Co doped were prepared through the solid-state reaction using conventional ceramic technique and no experiment was done on the same alloys as well as the results of that experiment. The compositions of the ferrite were $\mathrm{Co}_{0.02} \mathrm{Zn}_{0.20} \mathrm{Ni}_{0.58} \mathrm{Fe}_{2.2} \mathrm{O}_{4}$ and $\mathrm{Co}_{0.02} \mathrm{Zn}_{0.28} \mathrm{Ni}_{0.50} \mathrm{Fe}_{2.2} \mathrm{O}_{4}$. The raw materials $\mathrm{Fe}_{2} \mathrm{O}_{3}, \mathrm{NiO}$ and $\mathrm{ZnO}$ were mixed in a steel ball mill using deionized water for 3 hours then dried and presintered at $900^{\circ} \mathrm{C}$ for 5 hours. The presintered ferrite powders were crushed and mixed with $\mathrm{CoO}$ then wet milled for 6 hours. After drying, the resulting powders were mixed with $1 \mathrm{wt} \%$ polyvinyl alcohol (PVA) as a binder and uniaxiallly pressed into toroid and pellets at a pressure of a 1.2 and $2.2 \mathrm{ton} / \mathrm{cm}^{2}$, respectively. The compacts were successively sintered in a muffle furnace in air at a temperature of 1200, 1300 and 
$1350^{\circ} \mathrm{C}$ for 3 hours with an intermediate isothermal holding at $600^{\circ} \mathrm{C}$ for 4 hours to eliminate the PVA and finally furnace cooled to room temperature.

The bulk density of the pellet samples was determined after sintering at the above mentioned sintering temperatures. The single-phase spinel structure of the samples was confirmed by the X-ray diffraction method. The theoretical density of the samples has been calculated using the lattice parameter determined from X-ray data. Frequency dependent permeabilty has been measured up to the frequency of $10 \mathrm{MHz}$. The Curie temperature of the toroidal samples was determined from the temperature dependence of permeability by an Inductance Analyzer, WAYNE KEER, model 3255B using a laboratory-built tubular furnace.

\section{RESULTS AND DISCUSSION}

X-ray diffraction study of the samples indicates the homogeneous phase of perminvar ferrites. The X-ray diffraction (XRD) patterns of the samples are given in Fig. 1 which was obtained from $\theta-2 \theta$ geometry with $\mathrm{Cu}-\mathrm{K} \alpha$ radiation. In these figures the indices of the plane are shown in the parenthesis. The fundamental reflections from the planes of (111), (220), (311), (222), (400), (422), (511) and (440) characterize the perminvar ferrites. Reflection from the planes of (111), (222), (422), has been observed with weak intensities. The analysis of XRD patterns indicated that the studied Ni-Zn ferrite samples have spinel cubic structure with a homogeneous phase perminvar ferrite. The sharp peak reveals that the samples are in good crystalline form.

From the figures, one can clearly see that the lattice parameters increase both with temperature and $\mathrm{Zn}$ content. This increment may be related to the replacement of $\mathrm{Ni}^{2+}$ ion with smaller ionic radius $(0.83 \AA)$ by $\mathrm{Zn}^{2+}$ ion with slightly larger ionic radius $(0.87 \AA)$ (Chikazumi 1966). This difference in the lattice parameter may also be explained by the cation migration since $\mathrm{Zn}^{2+}$ ions on the A-sites exhibit a smaller ionic radius than on the B-sites because of covalence effects. The remarkable effect is the anomaly shift, due to the redistribution of the cations. This behavior is appeared clearly in the physical properties such as density, porosity and magnetic properties as authors will see later.

It is observed that the values of lattice constants obtained for sample $\mathrm{Co}_{0.02} \mathrm{Zn}_{0.20} \mathrm{Ni}_{0.58} \mathrm{Fe}_{2.2} \mathrm{O}_{4}$ are $8.369,8.372$ and $8.375 \AA$ for sintering temperature 1200, 1300 and $1350^{\circ} \mathrm{C}$, respectively. The values of lattice constants obtained for $\mathrm{Co}_{0.02} \mathrm{Zn}_{0.28} \mathrm{Ni}_{0.50} \mathrm{Fe}_{2.2} \mathrm{O}_{4}$ are 8.382, 8.383 and $8.384 \AA$ sintering temperatures of 1200 , 1300 and $1350^{\circ} \mathrm{C}$, respectively. Fig. 2 shows the temperature vs lattice constants $\mathrm{a}_{\mathrm{o}}$ for the compositions of $\mathrm{Co}_{0.02} \mathrm{Zn}_{0.20} \mathrm{Ni}_{0.58} \mathrm{Fe}_{2.2} \mathrm{O}_{4}$ and $\mathrm{Co}_{0.02} \mathrm{Zn}_{0.28} \mathrm{Ni}_{0.50} \mathrm{Fe}_{2.2} \mathrm{O}_{4}$, respectively. The bulk density $\left(d_{b}=\mathrm{m} / \mathrm{v}\right)$ of the studied samples were determined from the pellet samples after sintering at 1200,1300 and $1350^{\circ} \mathrm{C}$. The theoretical density $\left(\mathrm{d}_{\mathrm{x}}=8 \mathrm{M} / \mathrm{Na}_{\mathrm{o}}{ }^{3}\right)$ of the samples has been calculated using the lattice parameter, $\mathrm{a}_{0}$. The porosity of the 
investigated sample has been determined from the X-ray density and the measured bulk density using equation $\mathrm{P}=\left(1-\mathrm{d}_{\mathrm{b}} / \mathrm{d}_{\mathrm{x}}\right) 100$ and demonstrated in Table 1 .

Table 1. Lattice parameter, theoretical density, bulk density and porosity for the samples with the composition $\mathrm{Co}_{0.02} \mathrm{Zn}_{0.20} \mathrm{Ni}_{0.58} \mathrm{Fe}_{2.2} \mathrm{O}_{4}$ and $\mathrm{Co}_{0.02} \mathrm{Zn}_{0.28} \mathrm{Ni}_{0.50} \mathrm{Fe}_{2.2} \mathrm{O}_{4}$.

\begin{tabular}{lccccc}
\hline Composition & $\begin{array}{c}\text { Sintering } \\
\text { temperature } \\
\mathrm{T}_{\mathrm{S}}\left({ }^{\circ} \mathrm{C}\right)\end{array}$ & $\begin{array}{c}\text { Lattice } \\
\text { parameter, } \\
\mathrm{a}_{0}(\AA)\end{array}$ & $\begin{array}{c}\text { Theoretical } \\
\text { density, } \rho_{\mathrm{t}} \\
(\mathrm{g} / \mathrm{c} . \mathrm{c})\end{array}$ & $\begin{array}{c}\text { Bulk } \\
\text { density, } \rho_{\mathrm{b}} \\
(\mathrm{g} / \mathrm{c} . \mathrm{c})\end{array}$ & $\begin{array}{c}\text { Porosity, } \\
\mathrm{P}(\%)\end{array}$ \\
\hline & 1200 & 8.369 & 5.33 & 4.78 & 10.31 \\
$\mathrm{Co}_{0.02} \mathrm{Zn}_{0.20} \mathrm{Ni}_{0.58} \mathrm{Fe}_{2.2} \mathrm{O}_{4}$ & 1300 & 8.372 & 5.33 & 4.96 & 7.00 \\
& 1350 & 8.375 & 5.34 & 4.98 & 6.75 \\
& 1200 & 8.382 & 5.31 & 4.85 & 8.67 \\
$\mathrm{Co}_{0.02} \mathrm{Zn}_{0.28} \mathrm{Ni}_{0.50} \mathrm{Fe}_{2.2} \mathrm{O}_{4}$ & 1300 & 8.383 & 5.31 & 4.92 & 7.35 \\
& 1350 & 8.384 & 5.31 & 4.95 & 6.78 \\
\hline
\end{tabular}

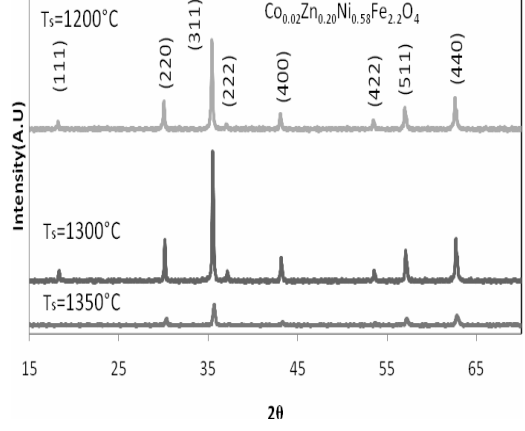

(a)

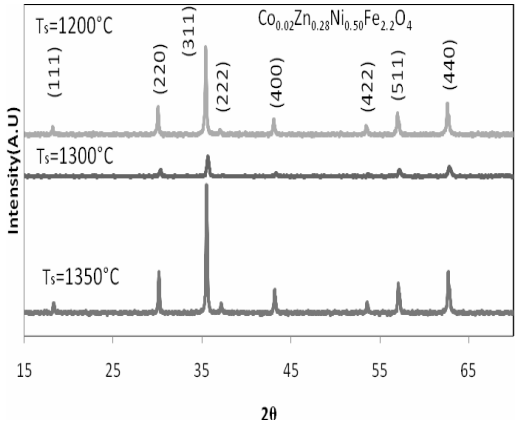

(b)

Fig. 1. X-ray diffraction pattern of (a) $\mathrm{Co}_{0.02} \mathrm{Zn}_{0.20} \mathrm{Ni}_{0.58} \mathrm{Fe}_{2.2} \mathrm{O}_{4}$ and (b) $\mathrm{Co}_{0.02} \mathrm{Zn}_{0.28}$ $\mathrm{Ni}_{0.50} \mathrm{Fe}_{2.2} \mathrm{O}_{4}$ ferrite samples at different sintering temperatures, respectively.

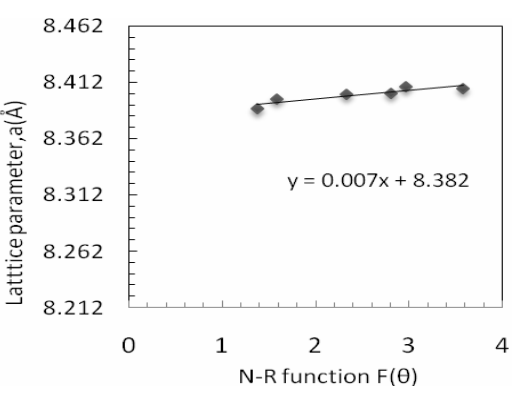

(a)

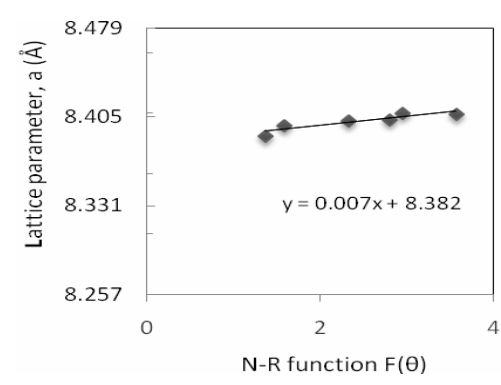

(b)

Fig. 2. Lattice parameter, $\mathrm{a}_{0}(\AA)$ vs temperature, $\mathrm{T}\left({ }^{\circ} \mathrm{C}\right.$ ) of (a) $\mathrm{Co}_{0.02} \mathrm{Zn}_{0.20} \mathrm{Ni}_{0.58} \mathrm{Fe}_{2.2} \mathrm{O}_{4}$ and (b) $\mathrm{Co}_{0.02} \mathrm{Zn}_{0.28} \mathrm{Ni}_{0.50} \mathrm{Fe}_{2.2} \mathrm{O}_{4}$, respectively.

Temperature dependence of permeability for the samples $\mathrm{Co}_{0.02} \mathrm{Zn}_{0.20} \mathrm{Ni}_{0.58} \mathrm{Fe}_{2.2} \mathrm{O}_{4}$ and $\mathrm{Co}_{0.02} \mathrm{Zn}_{0.28} \mathrm{Ni}_{0.50} \mathrm{Fe}_{2.2} \mathrm{O}_{4}$ has been measured and is shown in Fig. 3 from which the 
Curie temperatures, $T_{C}$ have been determined. It can be seen that $\mu^{\prime}$ increases with increasing sintering temperature attaining a maximum value just below $T_{C}$. The maximum value of $\mu^{\prime}$ just below the Curie temperature $\left(T_{C}\right)$, is a manifestation of Hopkinson peak attributed to the minimization of anisotropy energy with temperature. Beyond this peak value, initial permeability, $\mu^{\prime}$ sharply falls to very low value indicating the ferro-paramagnetic phase transition. $\mathrm{T}_{\mathrm{C}}$ has been taken as the temperature at which a sharp fall of permeability is observed i.e. where $d \mu / d T$ attains its maximum value. The sharpness of the fall of permeability indicates the homogeneity and the single phase of the studied samples, which have also been confirmed by X-ray diffraction by previous XRD study.

It is observed that the permeability falls sharply when the magnetic state of the ferrite samples changes and after that the permeability becomes smaller i.e. the paramagnetic character. It can be precisely said that the transition takes place from ferrimagnetic to paramagnetic at the Neel temperature $T_{N}$. The vertical drop of the permeability at the Curie point indicates the degree of homogeneity in the sample composition (Cedillo et al. 1980, Valenzula 1980). Further increasing temperature permeability becomes smaller and independent of temperature i.e. paramagnetic behavior. The used samples have showed an excellent degree of homogeneity. Measurement of the initial permeability as a function of temperature can therefore be used as a material characterization of that composition.

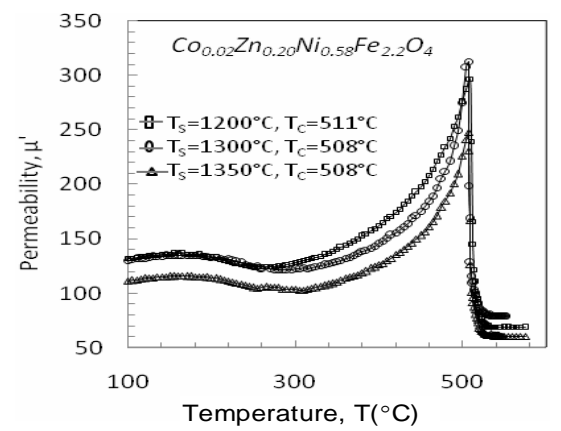

(a)

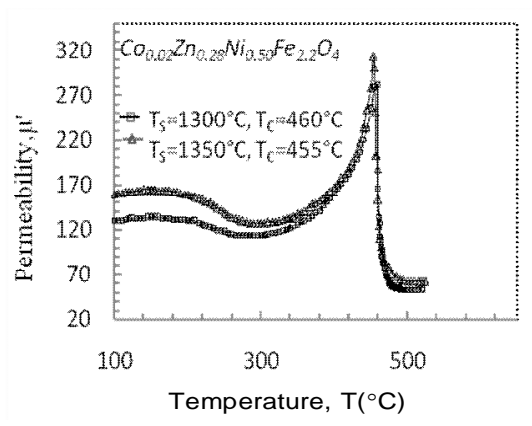

(b)

Fig. 3. Real part of permeability ( $\mu^{\prime}$ ) vs temperature (T) of (a) $\mathrm{Co}_{0.02} \mathrm{Zn}_{0.20} \mathrm{Ni}_{0.58} \mathrm{Fe}_{2.2} \mathrm{O}_{4}$ and (b) $\mathrm{Co}_{0.02} \mathrm{Zn}_{0.28} \mathrm{Ni}_{0.50} \mathrm{Fe}_{2.2} \mathrm{O}_{4}$ sintered ( $3 \mathrm{hrs}$ ) at different temperatures, respectively.

It is observed that the decrease of $\mathrm{T}_{\mathrm{C}}$ with $\mathrm{Zn}$ content may be explained by a modification of the A-B exchange interaction strength due to the change of the $\mathrm{Fe}^{3+}$ distribution between $\mathrm{A}$ and $\mathrm{B}$ sites when nonmagnetic $\mathrm{Zn}$ is substituted for $\mathrm{Ni}$. The basic magnetic properties of $\mathrm{CoFe}_{2} \mathrm{O}_{4}$ system originate from $\mathrm{Co}^{2+}$ ions only in the octahedral $\mathrm{B}$-sites since $\mathrm{Fe}^{3+}$ ions are distributed equally in both the $\mathrm{A}$ and $\mathrm{B}$-sites. The substituted $\mathrm{Zn}^{2+}$ preferentially occupies the tetrahedral A-site replacing an equal amount of $\mathrm{Fe}^{3+}$ to 
octahedral B-sites. In such a situation $\mathrm{J}_{\mathrm{AA}}$ becomes weaker resulting in the weakening of the strength of $\mathrm{J}_{\mathrm{AB}}$ exchange interactions, which reduces the Curie temperature, $\mathrm{T}_{\mathrm{C}}(\mathrm{Hu}$ Jun and Yan Mi 2005).

Fig. 4 shows the real part of permeability spectra for $\mathrm{Co}_{0.02} \mathrm{Zn}_{0.20} \mathrm{Ni}_{0.58} \mathrm{Fe}_{2.2} \mathrm{O}_{4}$ and $\mathrm{Co}_{0.02} \mathrm{Zn}_{0.28} \mathrm{Ni}_{0.50} \mathrm{Fe}_{2.2} \mathrm{O}_{4}$, respectively. The general characteristic of the spectra is that permeability, $\mu^{\prime}$ remains constant in a certain frequency range, while at higher frequencies, after a small rise, it begins to drop. From Fig. 4, it is found that the real part of the initial permeability increases with increasing sintering temperature for the samples $\mathrm{Co}_{0.02} \mathrm{Zn}_{0.20} \mathrm{Ni}_{0.58} \mathrm{Fe}_{2.2} \mathrm{O}_{4}$ and $\mathrm{Co}_{0.02} \mathrm{Zn}_{0.28} \mathrm{Ni}_{0.50} \mathrm{Fe}_{2.2} \mathrm{O}_{4}$, respectively. Nakamura (Hu Jun and Yan Mi 2005) also observed the permeability which increases with increasing sintering temperature for NiZnCo ferrites. It is clearly seen from Table 1 that grain size increases with increasing sintering temperature because the density increases with sintering temperature. The permeability increases with increasing grain size (Johnson et al. 1994, Wang et al.1981). Therefore, permeability increases with increasing sintering temperature. It is well-known that the permeability of polycrystalline ferrites is determined by the superposition of two mechanisms, i.e. spin rotation and domain wall motion. Large grains are fared to high permeability values because of the contribution of the domain wall (Zhenxing et al. 2001). The density of the materials increases with increasing sintering temperatures. It can be seen that there is an appreciable increase in the permeability with increasing density of the material, which appears to be connected with an increase in the contribution from domain wall displacement.

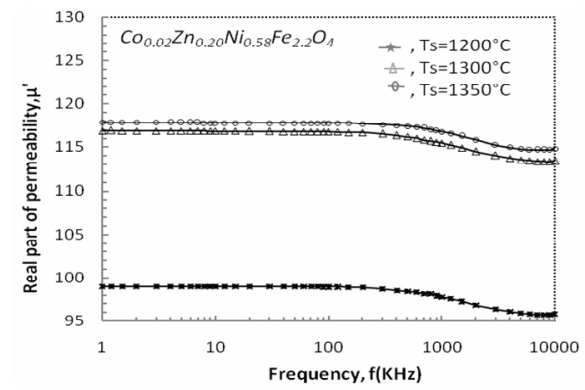

(a)

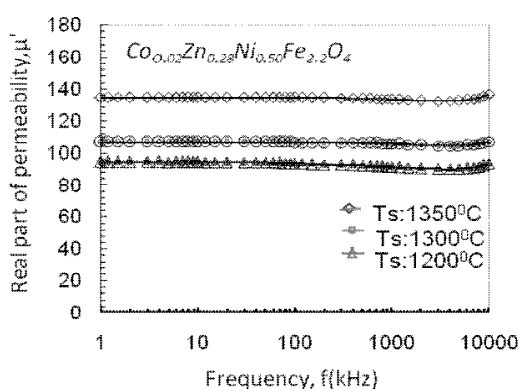

(b)

Fig. 4. Real part of permeability $\left(\mu^{\prime}\right)$ vs frequency, $\mathrm{f}(\mathrm{KHz})$ of the two studied samples sintered ( $3 \mathrm{hrs})$ at different temperatures, respectively.

It is also found from Fig. 3 that the initial permeability increases with increasing $\mathrm{Zn}$ content and with decreasing $\mathrm{Ni}$ content for $\mathrm{T}_{\mathrm{S}}=1350^{\circ} \mathrm{C}$. This increment may be related to the replacement of $\mathrm{Ni}^{2+}$ ion with smaller ionic radius $\left(0.83 \AA\right.$ ) by $\mathrm{Zn}^{2+}$ ion with larger ionic radius (0.87 $)$ (Hu Jun and Yan Mi 2005). It is observed from the Fig. 4 that the stability of permeability against frequency is quite high. Permeability is almost independent of frequency up to $\approx 10 \mathrm{MHz}$ and it gradually increases to higher frequency. 
For high frequency application this property of $\mu^{\prime}$-f stability is an important criterion. The permeability values for the studied samples remain independent of frequency. Resonance is not observed because authors' instrument can measure up to $13 \mathrm{MHz}$ frequency. But the samples resonance frequency is larger than that. So it was not possible to measure the resonance frequency of the samples.

The relative quality factor which determines the merit of the magnetic materials from the application point of view has been determined. The maximum relative quality factor has been found with the samples $\mathrm{Co}_{0.02} \mathrm{Zn}_{0.20} \mathrm{Ni}_{0.58} \mathrm{Fe}_{2.2} \mathrm{O}_{4}$ and $\mathrm{Co}_{0.02} \mathrm{Zn}_{0.28} \mathrm{Ni}_{0.50} \mathrm{Fe}_{2.2} \mathrm{O}_{4}$ as shown in Fig. 5. The maximum relative quality factor decreases and the frequency corresponding to the maximum relative quality factor increase as the $\mathrm{Zn}$ content increases as shown in Fig. 5. Also maximum relative quality factor varies as a function of frequency. For inductors used in filter applications, the quality factor is often used as a measure of performance. It is observed from the Fig. 5 that the samples $\mathrm{Co}_{0.02} \mathrm{Zn}_{0.20}$ $\mathrm{Ni}_{0.58} \mathrm{Fe}_{2.2} \mathrm{O}_{4}$ and $\mathrm{Co}_{0.02} \mathrm{Zn}_{0.28} \mathrm{Ni}_{0.50} \mathrm{Fe}_{2.2} \mathrm{O}_{4}$ sintered at $1200^{\circ} \mathrm{C}$ are of highest $\mathrm{Q}$ value which is probably due to the less imperfection and defects in them than all other samples. Smaller grain size is competent for larger $\mathrm{Q}$ values.

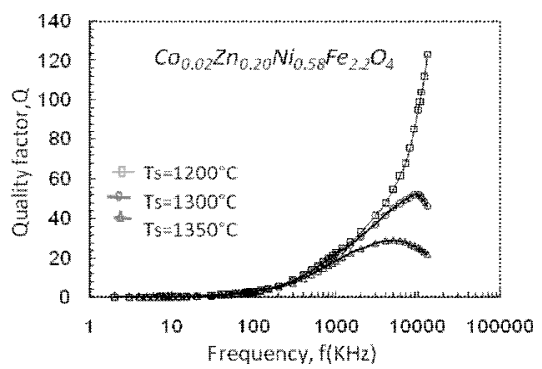

(a)

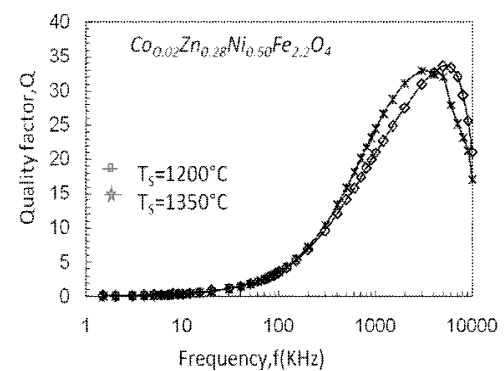

(b)

Fig. 5. Quality factor (Q) vs frequency, $\mathrm{f}(\mathrm{KHz})$ of (a) $\mathrm{Co}_{0.02} \mathrm{Zn}_{0.20} \mathrm{Ni}_{0.58} \mathrm{Fe}_{2.2} \mathrm{O}_{4}$ and

(b) $\mathrm{Co}_{0.02} \mathrm{Zn}_{0.28} \mathrm{Ni}_{0.50} \mathrm{Fe}_{2.2} \mathrm{O}_{4}$ sintered ( $3 \mathrm{hrs}$ ) at different temperatures, respectively.

\section{CONCLUSION}

Two different Ni-Zn perminvar ferrites having the composition $\mathrm{Co}_{0.02} \mathrm{Zn}_{0.20} \mathrm{Ni}_{0.58}$ $\mathrm{Fe}_{2.2} \mathrm{O}_{4}$ and $\mathrm{Co}_{0.02} \mathrm{Zn}_{0.28} \mathrm{Ni}_{0.50} \mathrm{Fe}_{2.2} \mathrm{O}_{4}$ sintered at 1200,1300 and $1350^{\circ} \mathrm{C}$ for 3 hours have been studied. The lattice parameters increase both with temperature and $\mathrm{Zn}$ content. The maximum value of $\mu^{\prime}$ just below the Curie temperature $\left(T_{C}\right)$, is a manifestation of Hopkinson peak attributed to the minimization of anisotropy energy with temperature. The Curie temperature, $\mathrm{T}_{\mathrm{C}}$ decreases with $\mathrm{Zn}$ content. It has been observed from the Fig. 5 that the sample $\mathrm{Co}_{0.02} \mathrm{Zn}_{0.20} \mathrm{Ni}_{0.58} \mathrm{Fe}_{2.2} \mathrm{O}_{4}$ and $\mathrm{Co}_{0.02} \mathrm{Zn}_{0.28} \mathrm{Ni}_{0.50} \mathrm{Fe}_{2.2} \mathrm{O}_{4}$ sintered at $1200^{\circ} \mathrm{C}$ are of highest $\mathrm{Q}$ value which is probably due to the less imperfection and defects in them than all other samples. 


\section{REFERENCES}

Cedillo, E., J. Ocampo, V. Rivera and R. Valenzula. 1980. An Apparatus for the measurement of initial magnetic permeability as a function of temperature. Journal of physics F: Scientific Instrument 13: 383.

Chikazumi, S. 1966. Physics of Magnetism. John Wiley \& Sons Inc., New York, 2nd Edition, pp. 295.

Hu Jun and Yan Mi. 2005. Preparation of high permeability of Ni-Cu-Zn ferrites. Journal of Zhejiang University Science 6: 580.

Johnson M. T., A. Noordermeer, M. M. E. Severin and W. A. M. Meeuwissen. 1994. Microstructural dependence of the complex permeability in fine grained $\mathrm{Mn}-\mathrm{Zn}$ ferrites. J. Magn. Magn. Mater. 116: 169.

Olofa, S. A. 1994. Microstructural dependence of the complex permeability in fine grained Mn-Zn ferrites. J. Magn. Magn. Mat. 131: 103.

Smart. J. Samuel. 1955. The Neel theory of ferromagnetism. Amer. J. Physics 23: 356.

Taniguchi, S. 1956. Sci. Rept. Res. Inst.Tohoku Univ., Japan AS. pp. 173.

Valenzula, R. 1980. A sensitive method for the determination of the curie temperature in ferrimagnets. Journal of material Science 15: 3137.

Wang, F. F. Y., K. M. Krisnan, D. E. Cox and T. G. Reynolds. 1981. Compositional and structural studies of a MnZn ferrite under different processing conditions. J. Appl. Phys. 52: 2436.

Zhenxing, Yue, Ji Zhou, Longtu Li and Zhilun Gui. 2001. Effects of $\mathrm{MnO}_{2}$ on the electromagnetic properties of Ni-Cu-Zn ferrites prepared by sol-gel auto-combustion. J. Magn. Magn. Mater. 233: 224 .

(Received revised manuscript on 3 July, 2011) 